\title{
Multidisciplinary approach in the anterior open bite using a McNamara expander with palatal crib during mixed dentition stage: A case report
}

(D) Wendes Dias Mendes ${ }^{1}$, (D) Pâla Caroline da Silva Mira ${ }^{2} \bowtie$, (D) Paula Regina Ávila Silvan ${ }^{3}$, (D) Patrícia Maria Monteiro $^{4}$, (Dirian Aiko Nakane Matsumot ${ }^{5}$, (D) Maria Bernadete Sasso Stuani ${ }^{6}$

\section{Highlights}

Pediatric dentists need to be aware of the multidisciplinary work involved in the treatment of anterior open bite as a result of its multifactorial etiology.
${ }^{1}$ Master's Degree Student, Department of Basic and Oral Biology, School of Dentistry of Ribeirão Preto, University of São Paulo (USP), Brazil

${ }^{2}$ PhD Student, Department of Pediatric Clinics, School of Dentistry of Ribeirão Preto, University of São Paulo (USP), Brazil

${ }^{3}$ PhD Student, Department of Pediatric Clinics, School of Dentistry of Ribeirão Preto, University of São Paulo (USP), Brazil

${ }^{4}$ Postdoctoral student, Department of Pediatric Clinics, School of Dentistry of Ribeirão Preto, University of São Paulo (USP), Brazil

5 Associate Professor, Department of Pediatric Clinics, School of Dentistry of Ribeirão Preto, University of São Paulo (USP), Brazil

${ }^{6}$ Associate Professor, Department of Pediatric Clinics, School of Dentistry of Ribeirão Preto, University of São Paulo (USP), Brazil
This case report presents an orthodontic treatment option based on the elimination of confounding factors during diagnosis of the malocclusion.
This article seeks to delegate competencies regarding the treatment of anterior open bite since the dentist is not able to fully intervene in some circumstances.

\section{Abstract}

Open bite can be defined as an absence of occlusion, most frequently located in the anterior region of dental arches and its etiology is multifactorial. We present a clinical case of an 8 years and 10 months child presenting an anterior open bite $(\mathrm{AOB})$ with transverse maxillary deficiency caused by tongue thrust during mixed dentition. The malocclusion was corrected by means of a McNamara expander with a palatal crib jointly with the association of speech therapy for tongue repositioning, and otolaryngology to treat adenoid hypertrophy due to its correlation with AOB. The multidisciplinary approach was effective in correcting the malocclusion with stable results after 2 years post-treatment.

Keywords: Interceptive Orthodontics; Malocclusion; Open Bite

\section{Correspondence: \\ Department of Pediatric Clinics, School of Dentistry of Ribeirão Preto, University of São Paulo (USP) E-mail address: paola.mira@usp.br}




\section{INTRODUCTION}

Open bite can be defined as the absence of occlusion primarily in the anterior region of the $\operatorname{arch}^{1}$ in the presence of negative overbite, while the posterior teeth are in contact. ${ }^{2}$

The etiology of anterior open bite (AOB) is considered multifactorial because a multitude of variables can work in the bone-dental configuration as well as in the magnitude of dysplasia associated with it.3,4 Therefore, several etiological factors are associated with the emergence of the $\mathrm{AOB}$, such as genetic factors and environmental, standing out in addition to harmful oral habits of non-nutritive sucking, tongue thrust, mouth breathing, and interposition of the tongue between dental arches. ${ }^{5}$

Genetic factors expressing skeletal AOB are due to craniofacial dysplasia and are characterized by a rotation of the palatine process in the counterclockwise direction, associated with an increased anteroinferior facial height, obtuse gonial angle, and the short mandibular ramus.,67 On the other hand, deleterious oral habits are more frequently associated with $\mathrm{AOB}$ of dental origin, which results from the interruption of the normal vertical development of the anterior teeth, while skeletal open bite results from an alteration in the vertical growth of the face. ${ }^{7}$

The AOB is considered challenging to develop a treatment plan that results in long-term stability, given that the solidity of the results is directly related to the diagnosis, etiology, and the time of intervention. ${ }^{6}$ Early intervention of AOB can prevent the installation of its permanent form ${ }^{8}$, as well as time consuming treatments whose long-term stability cannot be ensured, including orthodontic extrusion of anterior teeth, orthognathic surgery with impaction of the posterior region of maxilla, or by the management of posterior teeth eruption in growing patients. ${ }^{9,10}$

Within an early and multidisciplinary perspective approach, the development of a rational treatment plan that takes into consideration the different variants that may be associated with the presence of deleterious oral habits will allow that the timely interception can yield satisfactory and stable results in the functional and aesthetic perspective, in addition to the psychosocial gains that early intervention can offer to the child with this type of malocclusion.

Our objective is to report a clinical case of a dental AOB, corrected employing interceptive orthodontics associated with speech therapy and otolaryngology, during the mixed dentition stage.

\section{CASE REPORT}

An 8 years 10 months white female patient attended the Preventive and Interceptive Orthodontic Clinic of FORP/USP with the chief complaint of her anterior teeth were crowded. On extraoral examination was evidenced facial symmetry, good lip sealing, obtuse nasolabial angle, defined cervicomandibular angle, convex facial profile, and slightly increased facial lower third (Figure 1).
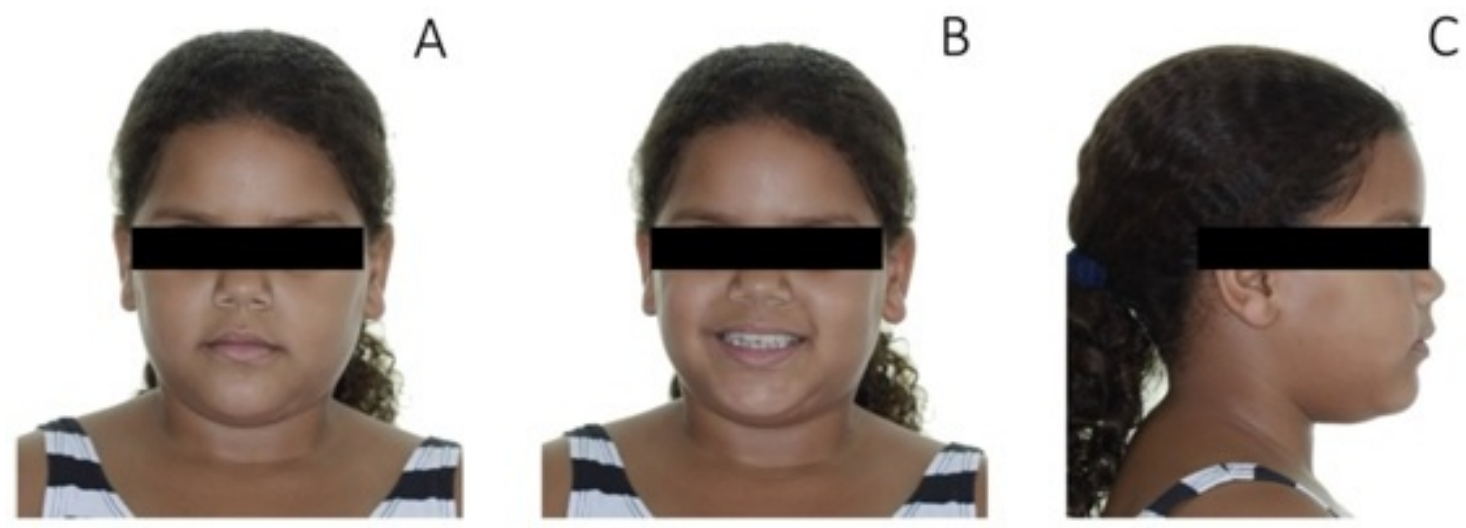

Figure 1. Initial extraoral photographs. A: Front; B: Front smiling; C: Right side 
In the functional examination, the patient was asked to retain some amount of water in her mouth for a few moments, to check whether there would be a need to use her mouth to breathe, resulting in the patient swallowing the liquid. At the moment of swallowing, the patient's lower lip was lowered to check for anterior projection of the tongue. It was observed mouth breathing and lingual thrust during deglutition characterizing the presence of atypical swallowing.

In the intraoral examination, the patient presented a molar Class III relationship subdivision left side, positive overjet $(2 \mathrm{~mm})$, and negative overbite $(-3 \mathrm{~mm})$ characterizing an AOB. and extensive crown destruction of teeth 74, which has already been endodontically accessed, as well as the presence of the first molars, lateral and central permanent incisors erupted. Her maxillary dental arch was skeletally constricted, the palate was ogival and V-shaped and the tooth size-arch length discrepancy was $-3 \mathrm{~mm}$ while in the lower arch was $+1.0 \mathrm{~mm}$ (Figure 2).

In panoramic radiography was verified the presence of all germs of permanent teeth, except for the 3rd molars, normality in the stage of rhizogenesis of the permanent teeth, and absence of peripicopathies. It was observed the premature loss of teeth 84

Due to the premature loss of teeth 84 , were observed the early eruption of tooth 44 and advanced rhizolysis of the roots of teeth 74 . The E-space was shown to be favorable to the permanent teeth eruption (Figure 3A).

In the lateral cephalometric radiograph (Figure 3B) and the cephalometric analysis (Table 1), showed the patient was skeletal Class I malocclusion $\left(\mathrm{SNA}=81^{\circ} ; \mathrm{SNB}=79^{\circ} ; \mathrm{ANB}=\right.$ $\left.2^{\circ}\right)$, therefore, the bone bases were wellpositioned to each other and with the anterior base of the skull.

Table 1. Initial and final cephalometric measurements

\begin{tabular}{llll}
\hline Magnitude & Normal & Initial & Final \\
\hline SNA & $82^{\circ} \pm 2$ & $81^{\circ}$ & $83^{\circ}$ \\
SNB & $80^{\circ} \pm 2$ & $79^{\circ}$ & $81^{\circ}$ \\
ANB & $0^{\circ} \mathrm{a} 4^{\circ}$ & $2^{\circ}$ & $2^{\circ}$ \\
SN.GoGn & $32^{\circ}$ & $33^{\circ}$ & $33^{\circ}$ \\
Sn.Gn & $68^{\circ}$ & $68^{\circ}$ & $69^{\circ}$ \\
Facial Axis & $90^{\circ}$ & $90^{\circ}$ & $91^{\circ}$ \\
1.NA & $22^{\circ}$ & $26^{\circ}$ & $24 \circ$ \\
1-NA & $4 \mathrm{~mm}$ & $5 \mathrm{~mm}$ & $4 \mathrm{~mm}$ \\
1.NB & $25^{\circ}$ & $25^{\circ}$ & $23^{\circ}$ \\
1-NB & $4 \mathrm{~mm}$ & $5 \mathrm{~mm}$ & $4 \mathrm{~mm}$ \\
1.1 & $131^{\circ}$ & $134^{\circ}$ & $130^{\circ}$ \\
S-Ls & $0 \mathrm{~mm}$ & $1 \mathrm{~mm}$ & $2 \mathrm{~mm}$ \\
S-Li & $0 \mathrm{~mm}$ & $0 \mathrm{~mm}$ & $-1 \mathrm{~mm}$ \\
NA.Pog & $-8^{\circ} \mathrm{a} 10^{\circ}$ & $3 \circ$ & $4{ }^{\circ}$ \\
\hline
\end{tabular}

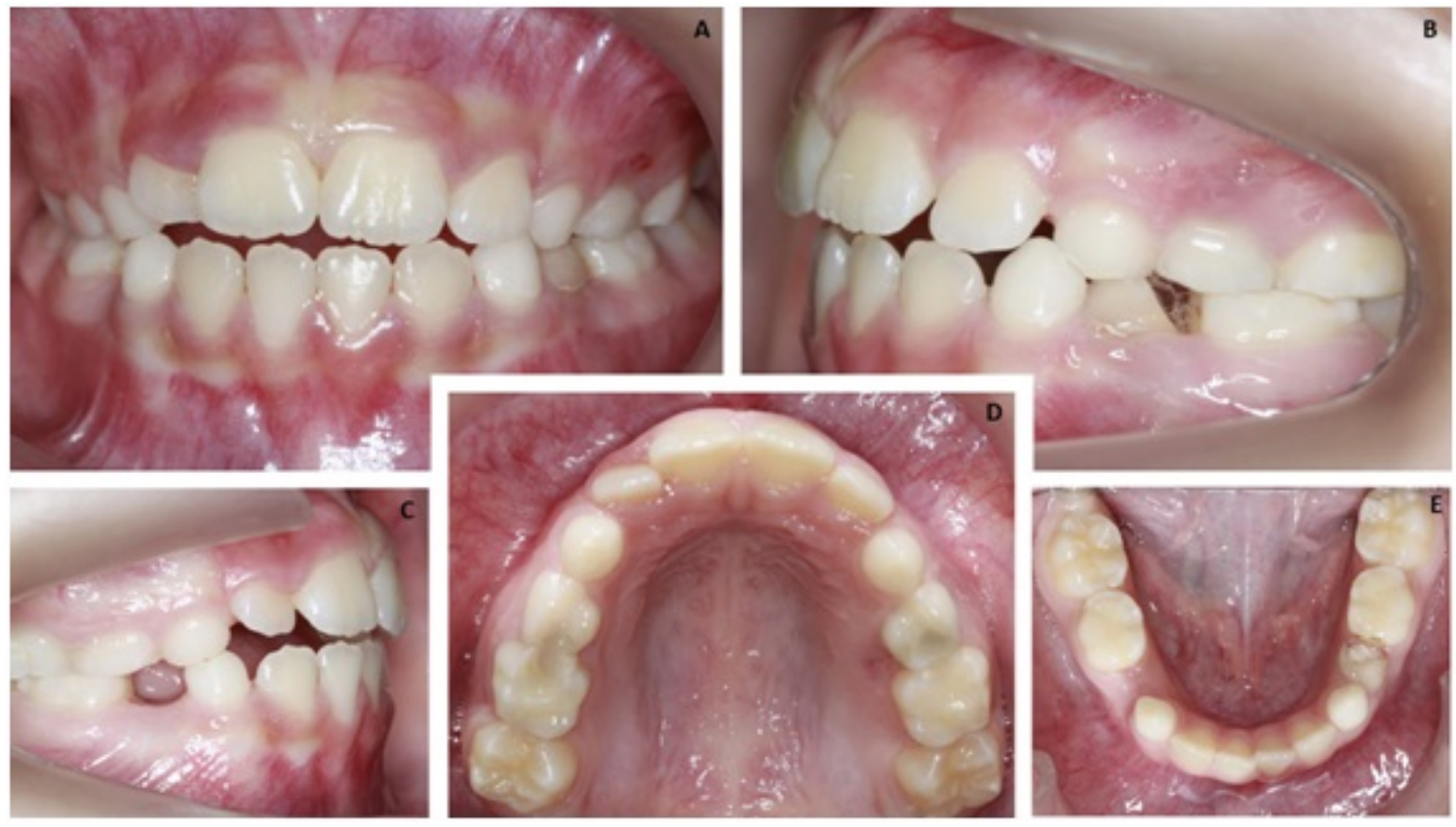

Figure 2. Initial intraoral photographs. A: Front; B: Left side; C: Right side; D: Upper occlusal; E: Inferior occlusal 

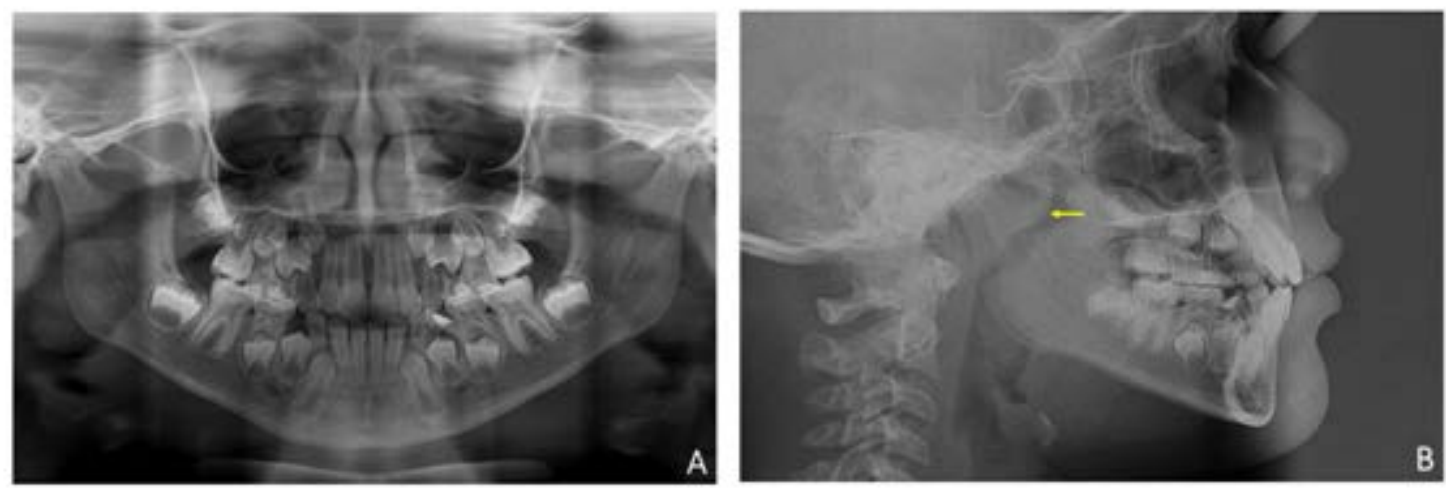

Figure 3. A: Initial panoramic radiograph; B: Initial lateral cephalometric radiograph suggesting the presence of hypertrophied adenoid tissue

Vertically, the mesofacial skeletal pattern was verified (SN.GoGn= 33o; SNGn= 68\%; Facial Axis $=90^{\circ}$. In relation to the dental pattern, the maxillary incisors were protruded $\left(1 . \mathrm{NA}=26^{\circ} ; 1\right.$ $\mathrm{NA}=5 \mathrm{~mm}$ ) and mandibular presented with suitable axial inclination, however, they were protruded in relation to the apical bone base $\left(1 . \mathrm{NB}=25^{\circ} ; \mathrm{NB}-1=5 \mathrm{~mm}\right)$. The soft-tissue profile was slightly convex $(\mathrm{S}-\mathrm{Ls}=1 \mathrm{~mm} / \mathrm{S}-\mathrm{Li}=$ $0 \mathrm{~mm}$ ) and the hard-tissue profile was straight $\left(\right.$ NA.Pog $\left.=3^{\circ}\right)$. There was also possible to be observed an enlarged radiopaque image in the posterior area of the nasopharynx suggestive of hypertrophy of the adenoids, which could be leading to the mouth breathing since the superior airways could be obstructed (Figure 3B).

Based on clinical and cephalometric findings, the AOB presented by the patient was diagnosed as a dental one, originating from the habit of tongue thrust during atypical swallowing. At the time, the prognosis was favorable, since the magnitude of the malocclusion was not severe and other possible confounding factors for the diagnosis were ruled out, making the correct diagnosis led to adequate treatment.

\section{Treatment plan}

At first, the treatment plan consisted of Rapid Maxillary Expansion (RME) through the installation of a modified McNamara expander associated with an anterior palatal crib (Figure 4A) and a lower lingual holding arch in the mandibular arch (Figure 4B) since the premature loss of tooth 84 has already occurred and, due to the great loss of tooth structure and advanced root resorption of teeth 74, was chosen for its extraction. The patient was also referred to an otolaryngologist (ENT) evaluation. The McNamara-type appliance is a bonded expander which is belived to present a better vertical control of posterior teeth due to its acrylic splint ${ }^{11}$. Therefore, in addition to expanding the maxilla, it would prevent the worsening of the anterior open bite, since for every $1 \mathrm{~mm}$ of posterior tooth extrusion, the bite opens in the anterior region twice this value. ${ }^{12}$

In the second phase, after the activation and retention period of the expander, was installed a removable appliance with a palatal crib and indicated speech therapy for the correct lingual position. This referral had to be done later since the fixed appliance on the palate would not allow the development of speech and articulation exercises. For the third planed phase, it was carried out monitoring the exfoliation of the remaining primary teeth and eruption of the permanent ones, for later referral to corrective orthodontics. 

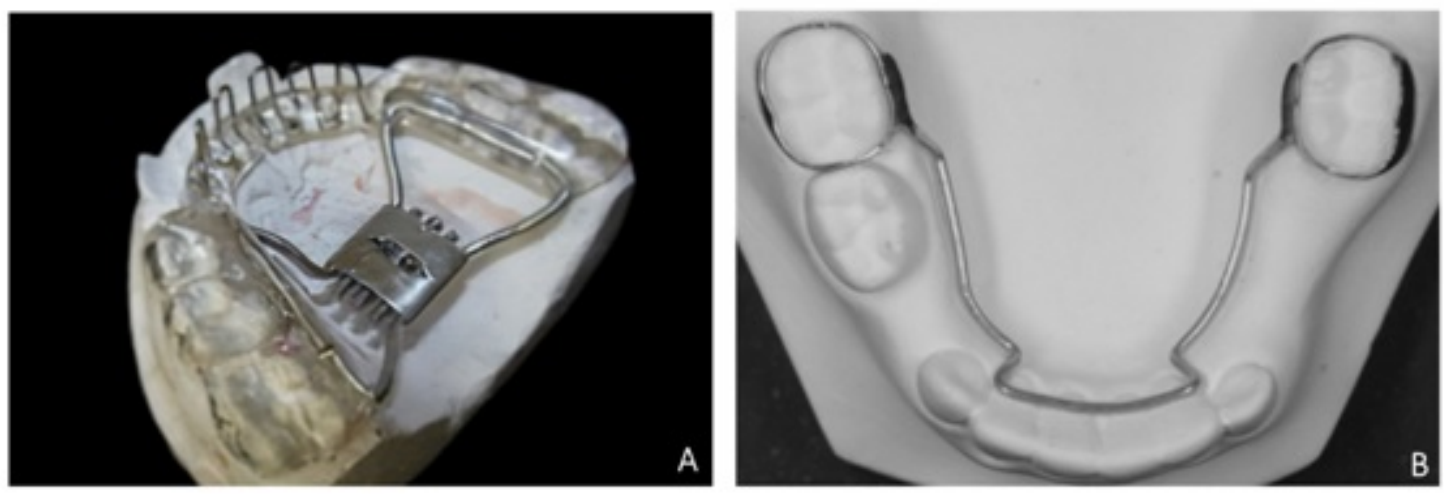

Figure 4. A: McNamara expander with vertical palatal crib; B: Illustrative photo of the lingual holding arch

\section{Treatment goals}

The first phase of the treatment aimed at gaining space in the maxilla for permanent teeth, correct the deep palate for better accommodation of the tongue, improvement in breathing and lip sealing. The choice of this type of appliance was due to its cost and ease of installation by the professional. The modified expander with palatal crib was carried out to provide the blocking of the interposition of the tongue during swallowing and combined with speech therapy and ENT approaches lead to correction of the dental anterior open bite. The lower lingual holding arch aimed at maintaining space, due to the premature loss of primary teeth 74 and 84 .

\section{Treatment alternatives}

The McNamara-type appliance is tooth-borne, but there is also a tooth-tissue-borne alternative, the Haas expander. We did not consider miniscrew-assisted rapid palatal expander (MARPE), which is a bone-borne device, since our patient was only 8 years old and still presented the midpalatal suture opening.

However, taking into account the need to intercept the atypical habit of protruding the tongue during swallowing, interceptive approaches to the habit would be necessary. The use of lingual spurs could also be employed; however, as we see this therapeutic option may cause pain in the child, we chose not to use it.

\section{Progress of treatment}

Although the maxillary transverse deficiency was not as severe, the patient presented mouth breathing and a negative maxillary dentoalveolar discrepancy. The modified McNamara expander was made with a Hyrax screw (Morelli, Brazil, $11 \mathrm{~mm}$ ) positioned centrally to the midpalatal suture in the region of the primary second molars. The vertical palatal crib was made of stainless steel $\varnothing 0,70 \mathrm{~mm}$ (.028") (Morrelli, Brazil). The central region of the crib was sectioned to allow the opening of the screw. The acrylic resin was added at the interface between the crib and the palatal mucosa to avoid damage to it. The acrylic occlusal covering of this type of appliance works as a "bite block" in the posterior segment of the arch, which prevents the extrusion of the maxillary posterior teeth, helping to close the bite. The activation protocol of the Hyrax screw was $2 / 4$ turns per day ${ }^{13}$, which corresponds to $0.5 \mathrm{~mm}$ of screw opening per day, with $1 / 4$ turn in the morning and a 1/4 turn at night, until the palatal cusps of the upper molars touch the buccal cusps of the lower molars. The expander screw was opened up to a width of $7 \mathrm{~mm}$ and the opening of the midpalatal suture was followed by occlusal radiography of the maxilla. After the activation period, there were 6 months of retention with the same device, with assisted control for ossification of the midpalatal suture. In addition to activating the expander, the patient was instructed about oral hygiene and care with the appliance. 


\section{Treatment result}

The patient was followed up monthly for one year, and her final orthodontic records were obtained two years after the correction of the $\mathrm{AOB}$, to monitor the stability of the case.

A satisfactory long-term result was obtained with the fixed vertical palatine crib coupled to the McNamara expander, speech therapy, and ENT, both in the facial (Figure 5) and occlusal aspects (Figure 6). The expander also provided space for the alignment of permanent maxillary anterior teeth, while the use of the vertical crib associated with speech therapy has contributed to the interception of tongue thrust and correction of atypical swallowing.

The lower lingual holding arch showed a benefic effect on the maintenance of the perimeter of the lower arch, which was a concern due to loss of primary teeth, however, it enabled the eruption of all permanent teeth (Figure 6), and the obtaining of positive overjet of about $2 \mathrm{~mm}$, and overbite of $3 \mathrm{~mm}$.
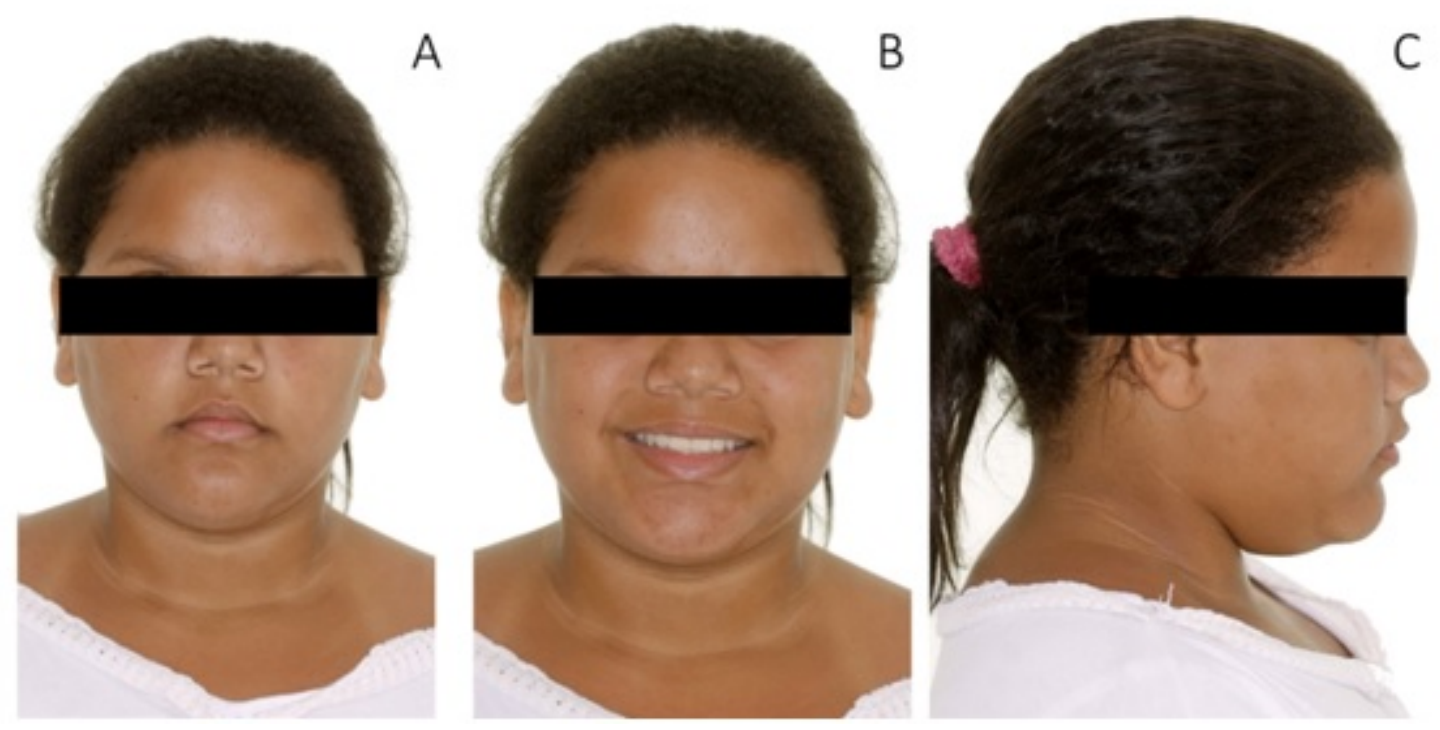

Figure 5. Final extraoral photographs. A: Front; B: Front smiling; C: Right side

The final panoramic radiograph did not show any periacopathy or root resorption. It was also possible to observe the germs of the lower third molars in an advanced stage of rhizogenesis (Figure 7A).

In the cephalometric analysis (Table 1), the bone bases kept in a good relation with each other $\left(\mathrm{ANB}=2^{\circ}\right)$, and the facial pattern remained mesofacial (SN.GoGn $=33 \circ$; SNGn $=69^{\circ}$; Facial Axis $=91 \circ$ ). The maxillary incisors $(1 . \mathrm{NA}=24 \mathrm{\circ} ; 1-\mathrm{NA}=4 \mathrm{~mm})$ and mandibular incisors $\left(1 . \mathrm{NB}=23^{\circ}\right.$; NB-1 $\left.=4 \mathrm{~mm}\right)$ were well positionated in relation to their apical base with a good interincisal relationship $\left(1.1=130^{\circ}\right)$. The integumentary profile was considered convex $(\mathrm{S}$ -
$\mathrm{Ls}=2 \mathrm{~mm} / \mathrm{S}-\mathrm{Li}=-1 \mathrm{~mm})$, and the bone profile straight $\left(\right.$ NA.Pog $=4^{\circ}$ ). It was also possible to verify that adenoid lymphoid tissue involuted, resulting in a wider space in the upper airway.

After the final orthodontic evaluation, it was possible to observe that the clinical case had a satisfactory and stable result after 2 years of intervention, requiring corrective orthodontics only for refinement of the case.

The prognosis due to the patient's age and the facial pattern was considered favorable. Furthermore, early correction provides stimuli that provide adequate craniofacial growth. 


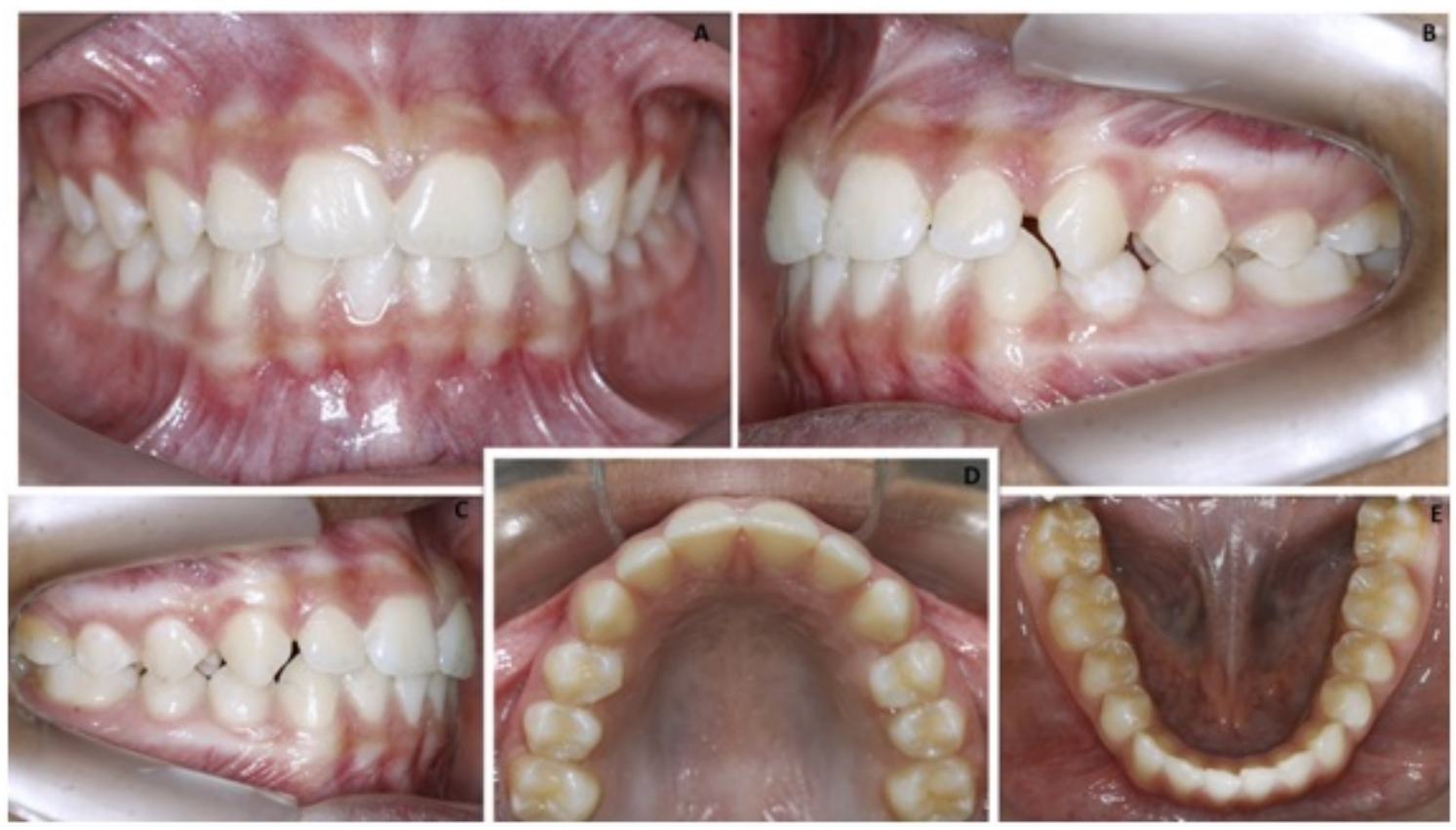

Figure 6. Final intraoral photos. A: Front; B: Left side; C: Right side; D: Upper occlusal; E: Inferior occlusal
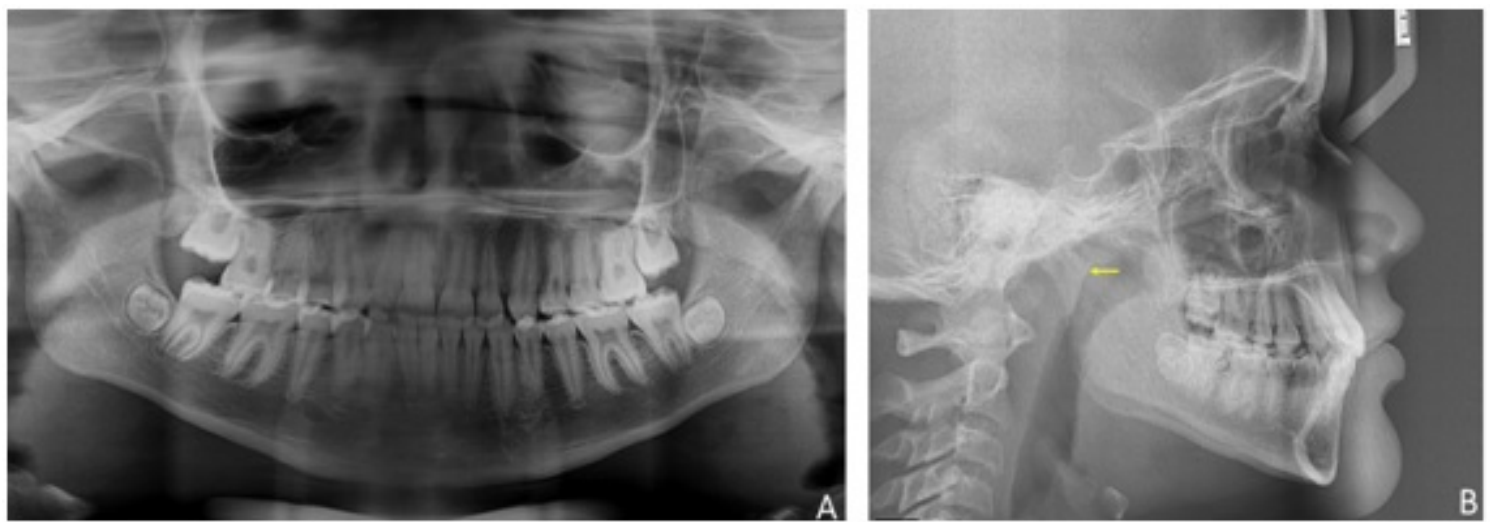

Figure 7. A: Final panoramic radiograph; B: Final lateral cephalometric radiograph showing adenoid tissue regression

\section{DISCUSSION}

Although the prevalence of $\mathrm{AOB}$ tends to decrease in patients in the mixed dentition ${ }^{8}$ as a result of predisposition to cease adopting deleterious oral habits, it is reported that the later the malocclusion is intervened, the chances of success and long-term stability decrease. ${ }^{14}$

The morphological configuration of the AOB presented by the reported patient showed a diffuse and narrow shape, not consistent with the interposition of a finger or a pacifier. Furthermore, anamnesis helped us to rule out the hypothesis of a prior non-nutritive sucking habit. As the cephalometric findings indicated that the patient had a mesofacial skeletal pattern $\left(\mathrm{SN} . G o G n=33^{\circ} ; \mathrm{SNGn}=69^{\circ} ;\right.$ Facial Axis $\left.=91^{\circ}\right)$, there was no skeletal predisposition to the onset of malocclusion, since there was no tendency of counterclockwise rotation of the palatal plane. ${ }^{15,16}$

The functional examination was essential to identify the tongue as the etiological agent of this $\mathrm{AOB}$, since when swallowing, the patient protruded the tongue anteriorly to prevent the escape of liquid and, thus, allow the swallowing to occur.

The study by Gutiérrez et al. ${ }^{17}$ showed that patients with AOB are more likely to present constriction of the anterior portion of the maxilla, as well as a smaller intercanine distance and deep palate. The authors attributed these conditions to the lowered positioning of the tongue during rest, which would cause an imbalance of forces 
between the tongue and the cheek muscles, leading to a lack of transverse stimulation of the maxilla. ${ }^{17}$ This lowered position of the tongue has also been correlated with an increase in the perimeter of the mandibular arch, as the teeth undergo its expansive pressure. ${ }^{17}$

Although our patient suffered a premature loss of tooth 84 and the E-space ${ }^{18,19}$ was still preserved, some space gain in the arch could also have occurred as a result of the lingual pressure, since it is clinically perceived that there was a slight loss of space by the mesialization of tooth 85, which was rotated (Figure 2E), but teeth 44 erupted without hindrance.

Although it is still controversial in the literature if the unusual position of the tongue comes as a result of a pre-existing condition or as the primary factor ${ }^{20}$, our patient presented a suggestive radiographic finding of hypertrophy of the adenoids (Fig. 3B), which could be leading to the mouth breathing. However, as the x-ray does not provide a three-dimensional visualization of the tissue volume, the patient was referred to the ENT, which carried out the nasal endoscopy for diagnosis. ${ }^{21,22}$ Although the adenoid suffers physiological hypertrophy up to approximately 7 years of age ${ }^{22,23}$, treatment with topical corticosteroids was used for regression of the lymphoid tissue ${ }^{24}$ (Figure 7B), as there were already evident craniofacial alterations, such as maxillary constriction.

In the maxillary arch, considering the narrow palate and the bone-tooth negative discrepancy presented by the patient, it was decided to proceed with RME. This procedure would provide, in addition to a gain in the arch perimeter $^{25}$, space for the tongue to be correctly accommodated on the palate, providing a character of normality in its positioning.

The removable cribs can be less effective than fixed by their dependence on the collaboration of the patient ${ }^{8}$, for this reason, and considering that the patient had reasonable oral health, despite the premature loss of two elements in the mandibular arch, the use of fixed appliance was the choice performed in the treatment plan.

The use of the McNamara expander type was given the advantage it provides, such as the ease of cleaning, not occurring irritation tissue due to the interposition of food between the palate and acrylic, as can occur more often with the Haas expander, and by the fact that the acrylic resin in the posterior region works as one bite block, preventing the extrusion the posterior maxillary teeth $^{26}$, which would lead to an increase in AOB.

The AOB originated from deleterious oral habits only cease after the removal of these factors $^{27}$, for this reason, the expander was modified with the addition of a vertical palatal crib, given they are devices very effective in trapping of $\mathrm{AOB}$ and that can restore the overbite up to $3 \mathrm{~mm}^{8}$.

It is worth noting that the momentary remission of the habit in virtue of the use of the appliance does not ensure the stability of correction, since it is necessary relearning the proper positioning of the tongue during swallowing and rest. ${ }^{26}$ Therefore, the speech therapy monitoring of the patient is essential for the success of the treatment.

\section{CONCLUSIONS}

It is concluded that the correct diagnosis based on the elimination of confounding etiological factors provides the necessary basis for carrying out the treatment plan for AOB based on tongue thrust origin. However, only the multidisciplinary treatment between speech therapy, otolaryngology, and the dentist will guarantee the success of the treatment. The rapid maxillary expansion through the McNamara expander associated with the fixed palatal crib is an adequate option for both the correction of anterior open bite and narrow palate, which ultimately favors the treatment and stability of the correction. 


\section{REFERENCES}

1- Moyers RE. Handbook of orthodontics. 4th ed. Chicago: Year Book Medical Publishers; 1988

2- Almeida RR, Ursi WJS. Anterior open bite; etiology and treatment. Oral Health 1990;80:27-31

3- Cangialosi TJ. Skeletal morphologic features of previous open bite. Am J Orthod 1984;85:2836

4- Tavares CAE, Allgayer S. Open bite in adult patients. Dental Press J Orthod 2019;24:69-78

5- Reis MJ, Pinheiro CN, Malafaia M. Treatment of anterior open bite: case report. Rev Clin Orthodon Dental Press 2007;6:88-96

6- Kline SN, Shensa DR, Kahn M. Skeletal open bite-surgical management: report of case. J Oral Surg 1970;28:791-794

7- Nahoum HI. Previous open-bite: a cephalometric analysis and suggested treatment procedures. Am J Orthod 1975;67:523-521

8- Feres MF, Abreu LG, Insabralde NM, de Almeida MR, Flores-Mir C. Effectiveness of open bite correction when managing deleterious oral habits in growing children and adolescents: A systematic review and meta-analysis. Eur J Orthod 2017;39:31-42

9- Espinosa DG, Moreira PEO, Sousa AS, FloresMir C, Normando D. Stability of anterior open bite treatment with molar intrusion using skeletal anchorage: a systematic review and metaanalysis. Prog Orthod 2020;21:35-37

10- Akan B, Ünal BK, Şahan AO, Kızıltekin R. Evaluation of anterior open bite correction in patients treated with maxillary posterior segment intrusion using zygomatic anchorage. Am J Orthod Dentofacial Orthop 2020;158:547-554

11- De Rossi M, De Rossi A, Abrão J. Skeletal alterations associated with the use of bonded rapid maxillary expansion appliance. Braz Dent J 2011;22:334-339

12- Scheffler NR, Proffit WR, Phillips C. Outcomes and stability in patients with anterior open bite and long anterior face height treated with temporary anchorage devices and a maxillary intrusion splint. Am J Orthod Dentofacial Orthop 2014;146:594-602
13- Haas AJ. Rapid expansion of the maxillary dental arch and nasal cavity by opening the midpalatal suture. Angle Orthod 1961;31:7390

14- Tanny L, Huang B, Shaweesh A, Currie G. Characterization of anterior open bite in primary school-aged children: a preliminary study with artificial neural network analysis. Int J Paediatr Dent 2021;31:576-582

15- Giuntini V, Franchi L, Baccetti , T, Mucedero M, and Cozza P. Dentoskeletal changes associated with fixed and removable appliances with a crib in open- bite patients in the mixed dentition . Am J Orthod Dentofacial Orthop 2008; 133:77-80

16- Flores-Ysla A, Arriola-Guillén LE, RodríguezCàrdenas YA, Ruíz-Mora GA, Aliaga-Del Castillo A, Janson G. Skeletal open bite cranial base characteristics in young Latin-American individuals with class I, II and III malocclusions: An observational study. Int Orthod 2020;18:237245

17- Gutiérrez DAR, Garzón JS, Franco JQ, Botero MP. Previous open bite and its relationship with dental arch dimensions and tongue position during swallowing and phonation in aged individuals 8-16 years: A retrospective case-control study. Int Orthod 2021;19:107116

18- Sonis A, Ackerman M. E-space preservation. Angle Orthod 2011;81:1045-1049

19- Lopes BK, Scheicher GV, Matsumoto MA, Romano FL. Rapid palatal expansion and utilization of e-space in mixed dentition: mechanics that helps in the corrective orthodontic treatment. Int J Clin Pediatr Dent 2021;14:133139

20- Kawamura M, Nojima K, Nishii Y, Yamaguchi H. A cineradiographic study of deglutitive tongue movement in patients with anterior open bite. Bull Tokyo Dent Coll 2003;44:133-139

21- Evcimik MF, Dogru M, Cirik AA, Nepesov MI. Adenoid hypertrophy in children with allergic disease and influential factors. Int J Pediatr Otorhinolaryngol 2015;79:694-697

22- Niedzielski A, Chmielik LP, Kasprzyk A, Stankiewicz T, Mielnik-Niedzielska G. HealthRelated Quality of Life Assessed in Children with Adenoid Hypertrophy. Int J Environ Res Public Health 2021;18:8935-8937 
23- Łapińska I, Zawadzka-Głos L. Adenoid and tonsils hypertrophy-symptoms and treatment. New Med 2016;20:103-106

24- Solmaz F, Așcıoğlu ME, Durgut O, Dikici O, Haksever M, Akduman D. Are nasal steroids effective in children with adenoid hypertrophy? European Res J 2019;5:311-318

25- Adkins MD, Nanda RS, Currier GF. Arch perimeter changes on rapid palatal expansion. Am J Orthod Dentofacial Orthop 1990;97:194199

26- Wendling L, Mcnamara J, Franchi L, Baccetti T. A Prospective Study of the Short- term Treatment Effects of the Acrylic-splint Rapid Maxillary Expander Combined with the Lower Schwarz Appliance. Angle Orthod 2005;75:714

27- Pisani L, Bonaccorso L, Fastuca R, Spena R, Lombardo L, Caprioglio. Systematic review for orthodontic and orthopedic treatments for previous open bite in the mixed dentition. Orthod Prog 2016;17:28-32

\section{How to cite this article:}

Wendes Dias Mendes, Paôla Caroline da Silva Mira, Paula Regina Ávila Silvano, Patrícia Maria Monteiro, Mirian Aiko Nakane Matsumoto, Maria Bernadete Sasso Stuani. Multidisciplinary approach in the anterior open bite using a McNamara expander with palatal crib during mixed dentition stage: A case report. Contemp Pediatr Dent 2021:2(3):161-175.

\section{Declarations}

Acknowledgements: Not applicable.

Conflict of Interest Statement: Authors disclose no potential conflicts of interest.

Ethics Statement: Procedure was explained to the parents and written consent was obtained for the treatment and publication of the case report.

Informed Consent: Informed consent was taken from parents.

Author contributions: Conception and design: All Authors; Acquisition of data: MBSS; Interpretation of data: PCSM; Drafting article: PCSM; Revision artice: WDM, PRAS, PMM, MANM; Final approval: All Authors

Funding: This work is not finantiated.

Data Availability: The data used to support the findings of this study can be made available upon request to the corresponding author.

Peer-review: Externally double-blinded peer-reviewed. 